\title{
Formação e Engajamento no Prefácio da Fenomenologia do Espírito de Hegel.
}

\author{
Luiz Henrique Vieira da Silva*
}

11 de agosto de 2008

E-MAIL: luizhenriquevieira@yahoo.com.br

\section{Resumo}

Resumo: Uma questão controversa existente entre os leitores e críticos da filosofia de Hegel residiria na de saber se ela seria, em toda sua extensão, uma filosofia engajada, se carregaria consigo uma vinculação com o real, ou se caberia no hegelianismo algum espaço para um discurso especulativo-abstrato descolado do real e da filosofia prática (ética e política). Para tentarmos iluminar de maneira breve esta questão, partiremos da reflexão sobre o pensamento, tema fundamental de Hegel, que se encontra no prefácio da Fenomenologia do Espírito.

Palavras chave: pensamento, real, espírito, história, especulativo

Abstract: There are two different ways of giving account of the spirit of Hegels philosophy. Fisrst, there are those who reads the hegelianism as something attached to history and to concrete practical (i. e. political and ethical) questions, as its very core and ultimate sense. Onthe other side there are some readers who find that sense more close to speculative and abstract thougth, or, at least, detached from the practical affairs in its last sense.

To understand more precisely what is the spirit of those reading's as regards the hegelian discourse itself, and particularly of the Phenomenology of Mind, we will spot down the trail of those options, and of the possible solutions of such a dilemma, following the clues given by the way which Hegel thinks the very concept of thinking.

Keywords: thinking, actuality, mind, history, speculative

\section{I}

É preciso investigar seriamente se, em seu todo, o hegelianismo é uma filosofia engajada, ou se, no final das contas caberia ainda, no interior do hegelianismo, espaço para um discurso puramente especulativo-abstrato - entendido este último como algo que deve ser pensado prescindindo-se do real e da filosofia prática

*Mestrando em Filosofia na UFPR. Instituição: Secretaria de Estado da Educação do Paraná - SEED/PR. 
(ética e política). Para tentar iluminar de maneira breve esta questão, partiremos da reflexão sobre o pensamento, reconhecidamente um tema fundamental de Hegel, mas o faremos a partir da forma como tal tema se encontra no prefácio da Fenomenologia do Espírito .

O Prefácio, antes de mais nada, insiste sobre a relação indelével entre a condição humana e o pesamento ele próprio. Tudo que pertence à condição humana pode ser resumido na possibilidade do reconhecimento, independentemente das diferenças culturais, geográficas, idiomáticas. Deste modo, se o pensamento permite reconhecer os homens por seu traço definitivo, como aquilo que dá a todos o reconhecimento de sua humanidade, será nos momentos em que Hegel examina o conceito de caráter que se apresentará a possibilidade de atribuir à função última do pensamento. Poderemos, então, divisar a resposta ao dilema entre uma filosofia especulativa e uma filosofia prática. Comecemos pelo princípio: toda ação humana, segundo prefácio, é também pensamento. Logo, as cidades, as formas de regime político, a religião, a arte, a guerra, a destruição e construção de civilizações, enfim, a cultura em geral, com toda sua história, se efetivam sob a guarda do pensamento.

Todavia, até então a palavra pensamento alcança um significado ainda muito vago, o que coloca certos problemas. O Primeiro deles pode ser o seguinte: como explicitar o trabalho do pensamento, pelo contraste com o que dele escapa, se sua ausência é o não pensamento? Esta explicitação, factualmente, se dá nos mitos, nas formas antigas de poesia, no modo como se constroem as cidades e suas leis. Factualmente esta dada, como jogo interno do pensamento e de seu objeto, a constante construção da cultura, na qual se confundem e se ramificam as várias ciências particulares diferentes até os nossos dias - formando a chamada consciência histórica (historisch) do homem ou de nossa humanidade.

O grande problema é que o homem no desenvolvimento de sua cultura (do pensamento portanto) secreta apenas a aparência de sua condição, uma vez fixadas as explicações incompletas, unilaterais do processo de formação da cultura. Em resumo, as ciências do finito envolvem algum desacordo com o pensamento, que nada mais é que sua própria aparência externa, seu ser-aí, exteriorizado já na forma de um mundo (inclusive o o social), sua casa. Tudo isso fará com que Hegel desenvolva uma filosofia que pretende mostrar o pensamento no seu desenvolvimento histórico (geschichtliche), criticando de maneira ácida o pensamento finito, de uma forma homóloga à crítica da razão, tendo como escopo, tanto quanto aquela, o próprio desenvolvimento da filosofia moderna como um todo. Todavia, diferentemente da crítica de uma razão teórica, o resultado desse esforço vai em direção à razão que se tornará ação, o espírito que transforma o mundo e, por isso, vincula-se ao real tornando-se efetivo.

A formação (Bildung) de cada cultura reside nesta efetividade. Deste modo, para Hegel, a formação alcançada pela filosofia coincide, e de certa forma reflete, a formação da consciência de cada época. Logo, quando o pensamento se apropria da filosofia, ao mesmo tempo herda e é formado em um saber efetivo, no qual exprime a consciência de seu tempo, se engaja nele, age no mundo. Quando o filósofo pensa a sua ciência, a sua sociedade e seu estado, não está apenas abstraindo, está também agindo e, por isso, sendo formado e formando. 
Este processo de formação histórica e cultural do pensamento é que o faz ação, isto é, o espírito que plasma sua época e forma seus pensadores, Mostraremos adiante como este movimento do pensamento é descrito por Hegel principalmente a partir do parágrafo trinta e dois do prefácio à Fenomenologia do Espírito de Hegel resultando numa concepção de formação que obriga o filósofo a ser engajado mesmo quando pensa no absoluto, pois o absoluto é o real ou o real é o absoluto, ou, seguindo o mote que Hegel apresenta posteriormente, nos Princípios da Filosofia do Direito: o Racional é Real e o Real é Racional.

\section{II}

No prefácio à Fenomenologia do Espírito Hegel apresenta o problema da cultura, do saber e da verdade, e como eles se desenvolvem na constituição da filosofia. O que equivale a dizer que, para Hegel, o papel da Fenomenologia do Espírito é mostrar o vir-a-ser da ciência em geral ou do saber. No entanto, podemos nos perguntar, de imediato, o que seria este "vir-a-ser do saber". Ora, o vir-a-ser do saber se mostra numa análise minuciosa dos desdobramentos desse mesmo saber em sua efetividade, o que significa, resumidamente, que coincide com um certo descompasso entre certeza e verdade que só se resolve no saber absoluto. Por certo, para Hegel, não se deve confiar nas representações bem conhecidas, com sua densidade meramente factual, mas procurar o caminho pelo qual se chegou a elas. E, somente depois disso, poderemos, então, determinar se tais representações dizem o que é (efetivamente), se são falsas — ou ainda, numa terceira opção, se não envolvem mera aparência.

Posta a questão nesses termos, cumpre então observar o nexo entre representação e verdade. O verdadeiro e o falso são determinações que pertencem aos pensamentos que, carentes de movimento, valem como essências próprias, as quais, sem ter nada em comum, permanecem isoladas. Contra tal posição deve-se afirmar que a verdade não é uma moeda cunhada, pronta para ser entregue e embolsada sem mais. Nem há efetivamente um falso nesse sentido, como tão pouco há um mal. O mal e o falso, na certa, não são tão facilmente demonizáveis, pois deles se fazem sujeitos particulares (como, por exemplo, se faz com o demônio). Como mal e falso, são apenas universais abstratos; não obstante têm sua própria essencialidade, um em contraste com o outro. O falso "pois só dele aqui se trata" seria o outro, o negativo da substância, a qual, por sua vez, é o verdadeiro, como conteúdo do saber.

Mas a substância mesma, ainda segundo Hegel, é essencialmente o negativo - em parte como diferenciação e determinação do conteúdo, em parte como um diferenciar simples — isto é, como "si" e "saber em geral". É bem possível saber falsamente. Saber algo falsamente significa que o saber está em desigualdade com sua substância. Ora essa desigualdade é precisamente o "diferenciar em geral". Mas tudo isso não se passa como como se a desigualdade fosse jogada fora, como a escória, do metal puro; nem tampouco como o instrumento que se deixa de lado quando o vaso está pronto. Ao contrário. A desigualdade como o negativo, como o si, está ainda presente ela mesma no verdadeiro como tal, imediatamente. Para Hegel, não se pode dizer por isso que o falso constitua 
um momento ou mesmo um componente do verdadeiro. Nesta expressão: "todo falso tem algo de verdadeiro", os dois termos contam como azeite e água que não se misturam, mas só se unem exteriormente. Não se devem mais usar as expressões de desigualdade onde o ser outro foi suprassumido:

“... justamente por causa da significação, para designar o momento do completo ser outro. Assim como a expressão da unidade do sujeito e do objeto, do finito e do infinito, do saber e do pensamento etc. tem o inconveniente de significar que o sujeito, o objeto etc. são fora de sua unidade; e, portanto, na unidade não são o que sua expressão enuncia, do mesmo modo o falso é um momento da verdade, mas não mais como falso".

Perceba-se, na passagem acima, que os conceitos de verdadeiro e falso não podem ser fundados em si mesmos, concretos em si mesmos, pois deste modo se apresentariam carentes de movimento não fazendo deste modo o desdobramento do seu próprio conceito e de seu outro, sendo deste modo duas essências separadas e distintas ao invés de uma essência única. Isto porque, segundo Hegel, o conceito tem um movimento interno e dialético, e este movimento faz que o conceito se desdobre no seu outro (no seu negativo, ou seja, no seu oposto). Neste caso, o verdadeiro se desdobrou no falso, seu outro.

Deste modo o falso é o negativo do verdadeiro, é a negação da substância nela mesma, isto é, o momento da diferenciação e determinação do conteúdo. E este é um momento essencial - momento realizado pelo entendimento, diga-se de passagem - pois através da diferença há a superação e ao mesmo tempo conservação das diferenças vindo-a-ser a igualdade, ou seja, a verdade. Logo, a verdade percorre um caminho no qual vem-a-ser, e o falso nada mais é do que um momento que se dá no desdobramento do conceito de verdade neste longo caminho de seu vir-a-ser. E este caminho de vir-a-ser onde o conceito se desdobra pondo seus diferentes conteúdos e depois os superando conservando, aflorando assim sua verdade, este também é o caminho do vir-a-ser do saber. Mas o caminho do vir-a-ser do saber só se dá por completo quando a consciência percorre todo o caminho da experiência e experimenta a si mesma:

"A experiência que a consciência faz aqui não é somente a experiência teorética, o saber do objeto, mas toda a experiência. Trata-se de considerar a vida da consciência tanto ao conhecer o mundo como objeto de ciência quanto ao conhecer-se a si mesma como vida, ou ainda quando ela se propõe uma meta. Todo o tipo de experiência ética, política, jurídica, religiosa, estética, física e química deve ser considerada pelo saber."

E é este movimento de experimentar todas as possibilidades da experiência, desde o campo da natureza ao do espírito, movimento feito pela consciência, que proporciona o vir-a-ser do saber (o pensamento). Este é um caminho árduo, no qual a impaciência não tem vez, em que o indivíduo deve se demorar 
em cada momento, porque os momentos são "figuras individuais completas" e considerados como um todo.

Precisamente esse movimento que faz a passagem por todos os momentos, por todas as figuras da consciência é, para Hegel, o movimento de formação cultural que a ciência apresenta. Esta experiência da consciência, movimento que percorre todos seus momentos, suas figuras, é a formação cultural envolvida na filosofia. Esta formação cultural, também, coincide com o movimento de vir-a-ser do saber.

Por fim, precisamos atentar para como o saber se desenvolve neste movimento. Vimos que a experiência em seu movimento tem vários momentos (figuras) as quais se deve percorrer, (mas com paciência, pois há um desenvolvimento interno em cada momento, "onde deve-se demorar junto dele". Este demorar é a "destruição" do momento (figura) para que se possa passar a outro, é o superarconservando os momentos para se chegar ao saber. É a força do negativo que deve agir nos conceitos, nas coisas, dilacerando-os completamente. Esta força está em tudo, está na vida: "a morte se assim quisermos chamar esta inefetividade" (a experiência com o nada, o vazio). Por isso, a vida do espírito é a que se conserva superando-se após o dilaceramento absoluto, após a destruição.

O espírito só alcança sua verdade à medida que se encontra no dilaceramento absoluto. Ele não é esta potência como o positivo que se afasta do negativo como ao dizer de alguma coisa que é nula ou falsa, liquidamos com ela e passamos a outro assunto. Ao contrário, o espírito só é essa potência enquanto encara diretamente o negativo e se demora junto dele . E é justamente esse demorarse, que é o destruir-construindo, o suprassumir ou o superar-conservando que faz a passagem do negativo em ser. Ou seja, que transforma o momento destruído em uma parte do todo. O que era meia-verdade ou falsidade agora é verdade. Deste modo, dentro do momento de formação cultural, a experiência feita pela consciência, o saber, aparece. Juntamente com ele a verdade, pois saber e verdade vindo à tona são o mesmo: o movimento da experiência destruindo cada momento em si, separando-o e radicalizando-o até a última conseqüência, eleva-o ao saber verdadeiro, ao saber do todo onde tudo já foi superado, mas ao mesmo tempo conservado, no qual a consciência, através da experiência, atingiu o espírito, entrou em acordo com o pensamento, mostrando a ele próprio que o mesmo se aliena, transformando-se em outro, o objeto de seu próprio si (a natureza).

Logo, a experiência da consciência, ao fazer todo o seu itinerário de formação cultural do indivíduo, demorando-se nele (experimentando o negativo e não só acumulando conhecimentos, fatos, conceitos, etc.), atinge o espírito mostrandoo como foi plasmando-se durante a história (agora sim: Geschichte) e como ele o é agora no seu tempo. Isto é, o indivíduo atinge o espírito do seu tempo, mas tomando consciência da sua manifestação ao longo da história.

\section{III}

Assim, após todo o itinerário da consciência e da sua ascensão ao espírito, e ele mesmo mostrando o destruir-construindo ou o superar-conservando do seu 
ser-outro, se dá por superada a separação entre saber (conhecimento) e verdade (o que há de essencial; no conhecimento).

Pois o que se sabe é saber do todo, ou seja, do essencial. Então, agora que o saber está efetivamente atingido, se encerra a Fenomenologia do Espírito e começa a filosofia especulativa ou a Lógica. Pois tudo agora (depois da Fenomenologia do Espírito) é conteúdo substancial ou o conceito. O Outro foi superado, destruído, e portanto adquiriu a forma do si. Deste modo, podemos observar o caráter pedagógico da Fenomenologia, pois ele pretende através da experiência da consciência, que exerce o movimento de formação cultural que percorre os momentos, os saberes e verdades, dar a formação cultural individual que, ao atingir o espírito do seu tempo (que é o mesmo que se manifesta durante toda a história), se torna também uma formação universal. E ao atingir essa formação universal na própria Fenomenologia do Espírito, já em seu prefácio, a filosofia de Hegel se apresenta também como saber enciclopédico.

Esse saber enciclopédico da filosofia não é, portanto, um somatório de todos os saberes. É um saber circular que percorre todos os saberes para justificá-los em termos de unidade racional num plano superior de abstração ou de universalidade desse conhecimento .

Logo, a Fenomenologia do Espírito é uma obra pedagógica de formação do Filósofo a partir não daquele que parte de conceitos, juízos ou qualquer outro fundamento; mas do Filósofo, o que enfrenta o pensamento percorrendo todos os seus momentos, demorando-se neles, compreendendo-os, para atingir o espírito e a sua manifestação no seu tempo. Assim compreendido o filósofo tem o direito de criticar seu tempo mostrando a manifestação do espírito destruindo conceitos e momentos que estão em voga, mas que já foram superados, e construindo novos que sempre estão atrasados segundo o movimento do espírito.

Assumir a história não significa ser edificante. Para dizer uma palavra sobre a pretensão de ensinar como o mundo deve ser, a filosofia sempre chega em todo caso tarde demais. Enquanto pensamento do mundo, só aparece na época em que a realidade concluiu o processo de sua formação e se completou. O que o conceito nos ensina, a história nos mostra com a mesma necessidade; é preciso esperar que a realidade tenha alcançado sua maturidade para que o ideal apareça em face do real e, após ter apreendido o mundo em sua substância, reconstrua-o na forma de um império das idéias.

Podemos concluir, então, dizendo que o saber apresentado na Fenomenologia do Espírito é um saber enciclopédico, porque dentro do sistema da obra - o que já se apresenta no prefácio — só se atinge o saber após todo o itinerário de formação cultural individual que alcança a formação cultural universal, adquirindo um caráter pedagógico de formação do Filósofo. E aí está a positividade do discurso hegeliano, justamente neste caráter de formação pedagógica do Filósofo que traz à tona uma filosofia engajada, enraizada na realidade concreta. Concreta porque leva em conta o teórico e o prático numa unidade historicamente construída e efetivada pelo homem que põe o positivo abstrato, o negativo e o positivo concreto, ou seja, nos ensina como a determinação (em sentido kantiano) necessita passar pela reflexão para novamente pôr-se como determinação, pois esse é o processo pelo qual a consciência apreende a si mesma e o mundo. 
Desta forma a filosofia hegeliana distancia-se de um discurso meramente vazio e afirma-se altamente vinculada ao real efetivo. 